\title{
Características florais e carpométricas e germinação in vitro de grãos de pólen de cultivares de amoreira-preta
}

\author{
Madeleine Alves de Figueiredo(1), Rafael Pio(1), Thaís Cristina Silva ${ }^{(1)}$ e Kelly Nascimento Silva(1) \\ (1)Universidade Federal de Lavras, Departamento de Agricultura, Caixa Postal 3.037, CEP 37200-000, Lavras, MG. E-mail: \\ madeleine_dede@yahoo.com.br, rafaelpio@dag.ufla.br, thais_cristina88@yahoo.com.br, kelly_1614@yahoo.com.br
}

Resumo - O objetivo deste trabalho foi avaliar as características florais e carpométricas, a viabilidade dos grãos de pólen e a capacidade germinativa de sementes de cultivares de amoreira-preta. Foram avaliadas as cultivares Brazos, Caingangue, Cherokee, Choctaw, Comanche, Guarani, BRS Tupy e Ébano. Utilizou-se um delineamento experimental inteiramente casualizado com as oito cultivares e dez repetições. Foram feitas avaliações quanto a: número de estames, carpelos, pétalas e sépalas; composição do meio de cultura; número de grãos de pólen por antera e por flor; taxa de germinação de grãos de pólen; percentagem de frutificação; massa de matéria fresca, dimensões e número de sementes dos frutos; massa e dimensões dos drupetes; e percentagem de emergência de plântulas. $\mathrm{O}$ meio de cultura estabelecido para as cultivares de amoreira-preta foi acrescido de $90 \mathrm{~g} \mathrm{~L}^{-1}$ de sacarose e $400 \mathrm{mg} \mathrm{L}^{-1}$ de ácido bórico, com pH aferido para 6,5 e meio solidificado com $8 \mathrm{~g} \mathrm{~L}^{-1}$ de ágar. 'Caingangue', 'Ébano' e 'BRS Tupy' apresentaram baixa germinação de grãos de pólen. 'Ébano' apresentou frutos arredondados e com poucos drupetes. 'Choctaw' e 'Comanche' apresentaram baixa percentagem de emergência de plântulas. 'Brazos' destacou-se na maioria das características avaliadas e é considerada como boa progenitora para programas de melhoramento genético.

Termos para indexação: Rubus, cultura de tecidos, emergência, frutas pequenas, polinização, melhoramento.

\section{Floral and fruit characteristics of blackberry cultivars, and in vitro germination of their pollen grains}

\begin{abstract}
The objective of this work was to evaluate the floral and fruit characteristics, pollen grain viability, and seed germination capability of blackberry cultivars. The cultivars Brazos, Caingangue, Cherokee, Choctaw, Comanche, Guarani, BRS Tupy and Ébano were evaluated. A completely randomized experimental design was used, with the eight cultivars and ten replicates. Evaluations were made for: number of stamens, carpels, petals, and sepals; basic composition of the culture medium; number of pollen grains per anther, and per flower; germination rate of pollen grains; percentage of fruiting; fresh biomass, dimension, and number of fruit seeds; mass and dimension of drupets; and percentage of seedling emergence. The established culture medium for the cultivars was added with $90 \mathrm{~g} \mathrm{~L}^{-1}$ sucrose and $400 \mathrm{mg} \mathrm{L}^{-1}$ boric acid, with adjusted $\mathrm{pH}$ to 6.5 , and solidified medium with $8 \mathrm{~g} \mathrm{~L}^{-1}$ agar. 'Caingangue', 'Ébano' and 'BRS Tupy' showed low-pollen grain germination. 'Ébano' showed round fruit with few drupets. 'Choctaw' and 'Comanche' had low percentage of seedling emergence. 'Brazos' stood out for most of the evaluated characteristics, and it is considered as a good parent for breeding programs.
\end{abstract}

Index terms: Rubus, tissue culture, emergency, small fruit, polinization, breeding.

\section{Introdução}

Os cultivos com amoreira-preta (Rubus spp.) no Brasil se iniciaram com o lançamento das primeiras cultivares (Negrita, Ébano, BRS Tupy, Guarani e Caingangue), pelo programa de melhoramento genético da Embrapa Clima Temperado. Essas cultivares são dotadas de espinhos, o que dificulta as operações de poda e colheita. Uma opção seria o cultivo de cultivares adequadas à colheita mecânica, como a Cherokee e Comanche (Raseira \& Franzon, 2012), ou sem espinhos, como a Ébano.

Antunes et al. (2000) registraram produtividade de $3.257 \mathrm{~kg} \mathrm{ha}^{-1}$ em plantas da cultivar Ébano, em Caldas, MG, que é bem inferior ao registrado pela cultivar Brazos, que atingiu $16.357 \mathrm{~kg} \mathrm{ha}^{-1}$ já no primeiro ciclo produtivo. Porém, 'Brazos' produz frutos ácidos, impróprios para o consumo ao natural, e apresenta espinhos (Guedes et al., 2013). A cultivar Guarani apresenta boa produtividade (Campagnolo \& 
Pio, 2012b), mas seus frutos têm sabor inferior aos da BRS Tupy (Raseira \& Franzon, 2012), que produzem frutos com bom equilíbrio entre açúcares e acidez, assim como a cultivar Caingangue (Campagnolo \& Pio, 2012b). No entanto, Campagnolo \& Pio (2012c) registraram produtividade de $6.430 \mathrm{~kg} \mathrm{ha}^{-1}$, em plantas da cultivar BRS Tupy, em Marechal Cândido Rondon, PR. Outras opções para regiões subtropicais seriam a 'Choctaw' e a 'Caingangue', que apresentam baixa necessidade de frio (Raseira \& Franzon, 2012). Assim, nota-se que há necessidade de se intensificar o programa de melhoramento de amoreira-preta no Brasil, para a seleção de cultivares com produtividade que possa chegar até $25.000 \mathrm{~kg} \mathrm{ha}^{-1}$ por ano (Antunes et al., 2000), sem espinhos, aptas a serem cultivadas em regiões subtropicais e que também apresentem frutos com qualidade superior.

Para dar suporte aos programas de melhoramento, o conhecimento das características florais e carpométricas dos germoplasmas disponíveis são de suma importância para a seleção dos progenitores a serem utilizados nas hibridações (Clark, 2008), assim como a viabilidade dos grãos de pólen e a capacidade germinativa que permite a avaliação mais rápida das progênies obtidas nos cruzamentos e maior quantidade de plântulas melhoradas.

Em razão da ocorrência de poliploidia, agamospermia e hibridação entre as espécies, a taxonomia da amoreira-preta é complicada (Alice, 2002). Ela apresenta flores com múltiplos ovários e estames e produz frutos agregados (Clark \& Finn, 2011). A amoreira-preta produz em ramos de ano (Antunes et al., 2004), e algumas de suas cultivares melhoradas também produzem em ramos do ano (Clark, 2008). O período anual de floração da amoreira-preta é curto, com início no mês agosto e término em janeiro (Campagnolo \& Pio, 2012b) e, se os grãos de pólen estiveram inférteis, o cruzamento fica comprometido. $\mathrm{Na}$ natureza, a única maneira de se verificar a viabilidade dos grãos de pólen é por meio da realização de cruzamentos em campo e posterior avaliação das progênies. Porém, é um processo oneroso, pois, grãos de pólen inviáveis não permitem os trabalhos de cruzamento artificial, já que os óvulos não fecundam e, consequentemente, não ocorre a formação de frutos e sementes. Uma alternativa mais rápida e confiável seria a utilização de testes in vitro.
Há uma relação entre a percentagem de germinação e a viabilidade do pólen (Bolat \& Pirlak, 1999). O pH do meio de cultura também influencia a germinação e a viabilidade dos grãos de pólen (Ramos et al., 2008; Chagas et al., 2010).

O objetivo deste trabalho foi avaliar as características florais e carpométricas, a viabilidade dos grãos de pólen e a capacidade germinativa de sementes de cultivares de amoreira-preta.

\section{Material e Métodos}

O experimento foi realizado no ano de 2011, na Universidade Federal de Lavras (Ufla), Lavras, MG. O clima do local é do tipo Cwb, conforme classificação de Köppen. As seguintes cultivares de amoreira-preta (Rubus spp.) foram utilizadas: Brazos, Caingangue, Cherokee, Choctaw, Comanche, Guarani, BRS Tupy e Ébano; esta última não apresenta espinhos.

As mudas das cultivares de amoreira-preta foram plantadas em campo, em novembro de 2009, em espaçamento $3,0 \times 0,5 \mathrm{~m}$ (densidade de 6.667 plantas ha ${ }^{-1}$ ). As plantas foram conduzidas sob espaldeira simples de um fio em $\mathrm{T}$ e com fios duplos paralelos, espaçados em $60 \mathrm{~cm}$ de distância e a $80 \mathrm{~cm}$ de altura do solo. Realizou-se o controle das plantas espontâneas, em toda a área experimental, e aplicaramse $3 \mathrm{~L}$ por metro linear de matéria orgânica por duas vezes, uma em outubro e outra em dezembro, em cada ano de cultivo. Realizou-se a análise do solo no mês de maio de cada ano, para detecção de possíveis deficiências nutricionais e, posteriormente, aplicaramse os corretivos e fertilizantes necessários. Para a manutenção das plantas, $200 \mathrm{~g}$ de sulfato de amônio foram aplicados por duas vezes, uma em setembro e outra em janeiro, além de $100 \mathrm{~g}$ de superfosfato simples, $100 \mathrm{~g}$ de cloreto de cálcio e $150 \mathrm{~g}$ por metro linear de calcário (em abril).

Para a caracterização floral, foram coletados, aleatoriamente, 10 botões florais de cada cultivar, no estádio "balão" (Figura 1 A), no período da manhã, que foram transportados para o Laboratório de Pomologia da Ufla, em placas de Petri fechadas. Realizou-se a contagem do número de estames, de carpelos, pétalas e sépalas (Figura 1 B). Cada botão floral representou uma repetição, no total de dez repetições por cultivar estudada. Utilizou-se o delineamento inteiramente 
casualizado, e os tratamentos foram compostos pelas oito cultivares.
Para a contagem do número de grãos de pólen, por antera e por flor, foram coletados 10 botões florais

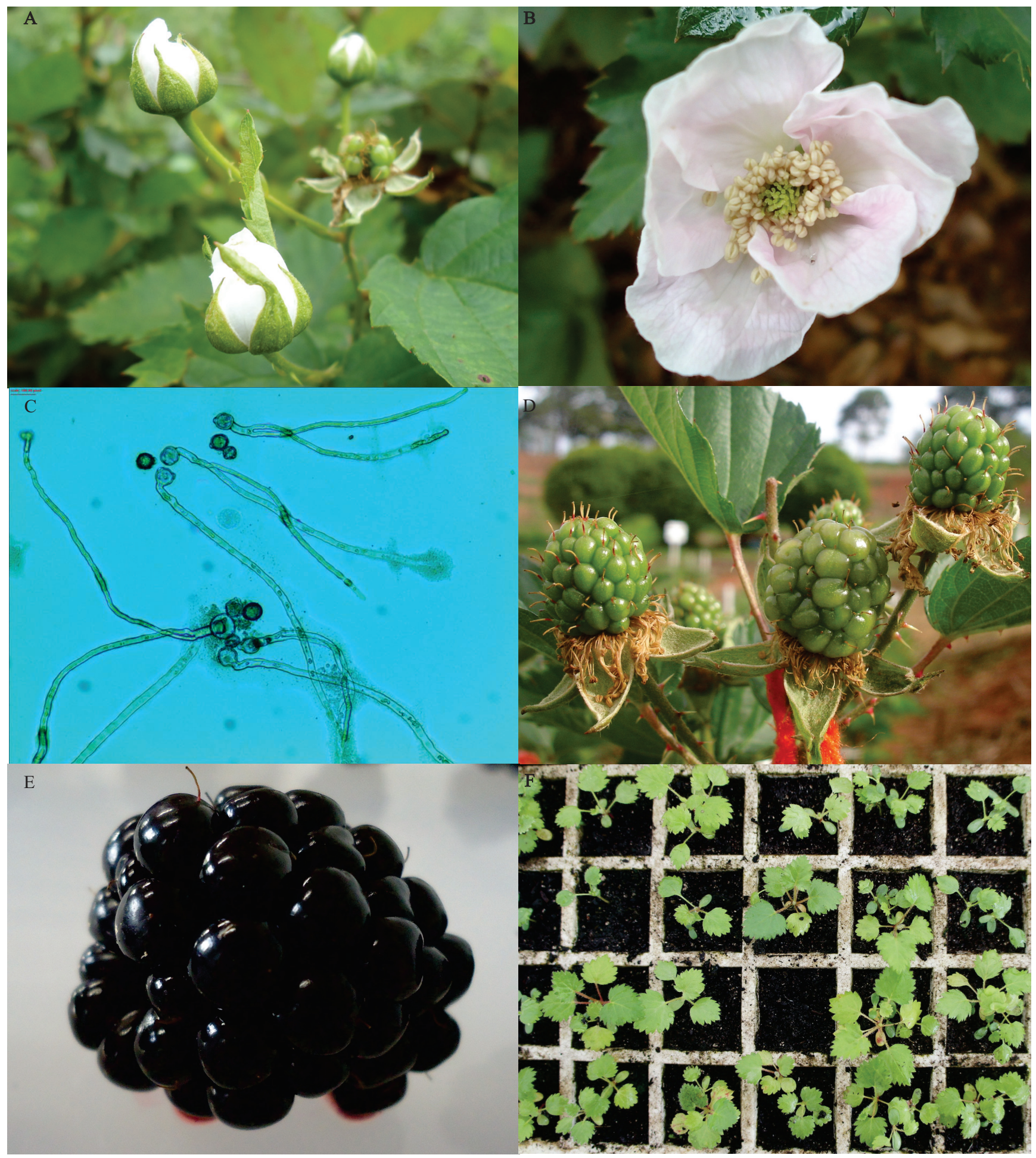

Figura 1. Cultivares de amoreira preta (Rubus spp.): A, botões florais ('Choctaw'); B, detalhe de pétalas, estames e carpelos da flor ('Guarani'); C, grãos de pólen germinados in vitro ('Comanche'); D, frutificação ('Cherokee'); E, fruto maduro ('BRS Tupy'); e F, emergência de plântulas ('Brazos'). Fotos: Madeleine Alves de Figueiredo. 
de cada cultivar, em estádio balão, e 15 anteras foram retiradas de cada botão de forma aleatória, por intermédio de uma pinça; cada conjunto de anteras foi armazenado em tubos de Eppendorf, que ficaram destampados à temperatura ambiente por 12 horas sem luz, para que ocorresse a antese - completa deiscência e liberação do polínio - conforme Ramos et al. (2008).

Após a deiscência, uma solução de $1.000 \mu \mathrm{L}$ de ácido lático foi adicionada aos tubos, que continuaram tampados e mantidos à temperatura ambiente, em local sem iluminação. Após 48 horas, uma amostra da solução $(10 \mu \mathrm{L})$ com os grãos de pólen liberados foi depositada em lâmina de leitura (Neubauer), para que se realizasse a contagem de grãos de pólen com auxílio de microscópio óptico (100X) (Pio et al., 2005). $\mathrm{O}$ experimento foi conduzido com dez repetições, e cada repetição foi constituída por quatro leituras em lâmina de Neubauer.

A quantidade de grãos de pólen, em cada antera, foi calculada pela multiplicação da média do número de grãos de pólen de cada amostra (tubo de Eppendorf) pelo volume do ácido lático da solução $(1.000 \mu \mathrm{L})$. O valor resultante foi dividido pelo produto da multiplicação entre o volume de ácido lático da amostra $(10 \mu \mathrm{L}) \mathrm{e}$ o número de anteras de cada tubo (15). $\mathrm{O}$ número de grãos de pólen por flor foi calculado pela multiplicação da estimativa média de grãos de pólen por antera pelo número médio de anteras por flor. Esta experimentação também foi conduzida com dez repetições, em delineamento inteiramente casualizado, em que os tratamentos foram compostos pelas oito cultivares estudadas.

Para a determinação da composição do meio de cultura, para a maximização da germinação dos grãos de pólen, utilizou-se a 'Comanche', em razão de seu florescimento precoce comparado ao das demais cultivares. Abaixo estão listados os testes realizados para o estabelecimento do meio de cultura. Para cada teste, anteras de 120 botões florais da 'Comanche', coletados pela manhã, foram retiradas por intermédio de uma pinça e armazenadas em placas de Petri destampadas e mantidas à temperatura ambiente por 12 horas, sem luz, para que ocorresse a antese, com completa deiscência e liberação do polínio, conforme Ramos et al. (2008).

O polínio da 'Comanche' foi utilizado para a instalação dos seguintes testes: concentração de ágar $\left(4,6,8\right.$ e $\left.10 \mathrm{~g} \mathrm{~L}^{-1}\right)$ vs $\mathrm{pH}$ do meio $(3,5,4,5,5,5 \mathrm{e}$
6,5); concentração de sacarose $\left(0,30,60,90 \mathrm{~g} \mathrm{~L}^{-1}\right)$; concentrações de nitrato de cálcio $(0,200,400$, $\left.800 \mathrm{mg} \mathrm{L}^{-1}\right)$ vs concentração de ácido bórico (0, $400,800,1.200 \mathrm{mg} \mathrm{L}^{-1}$ ); e tempo de emissão do tubo polínico a $0,1,2,3,4,5$ e 6 horas após inoculação.

Os testes foram instalados de forma sequencial, ou seja, a concentração dos componentes químicos que propiciaram a melhor germinação dos grãos de pólen, no primeiro teste, foi utilizada nos testes seguintes. Assim, o teste do tempo de emissão do tubo polínico foi instalado no meio de cultura com as melhores concentrações dos componentes químicos dos testes anteriores, as quais propiciaram a melhor germinação dos grãos de pólen.

$\mathrm{O}$ meio foi incubado em laboratório, em condições controladas (temperatura média de $27^{\circ} \mathrm{C}$ ), conforme Chagas et al. (2010). Para cada teste, o polínio foi distribuído, por intermédio de um pincel, sobre a superfície das placas de Petri com $20 \mathrm{~mL}$ de meio de cultura, de modo a promover uma distribuição homogênea. Após aproximadamente quatro horas de incubação, com exceção do experimento de diferentes tempos de emissão do tubo polínico, foram contados, com auxílio de lupa monocular com objetiva de 10X, os grãos de pólen germinados ou não. Foram considerados germinados os grãos de pólen cujo comprimento do tubo polínico ultrapassou o dobro do próprio diâmetro (Chagas et al., 2010) (Figura $1 \mathrm{C}$ ).

Todos os quatro testes foram realizados com quatro repetições, e cada repetição foi composta por um quadrante da placa de Petri e constituída por cinco campos de visão, observados através da lupa monocular. $\mathrm{O}$ delineamento inteiramente casualizado foi utilizado, e os tratamentos de cada teste foram compostos dos seguintes fatores: concentrações dos compostos químicos, para os três primeiros testes; e horas, para o último teste.

Após estabelecer o meio de cultura específico, assim como o tempo de emissão do tubo polínico de grãos de pólen da amoreira-preta, os polínios de cada cultivar estudada foram submetidos à cultura in vitro, para a avaliação das taxas de germinação de grãos de pólen, conforme Chagas et al. (2010). Esse experimento foi conduzido com quatro repetições, e cada repetição foi composta por um quadrante da placa de Petri. Cada repetição foi constituída por cinco campos de visão, observados através da lupa monocular. Utilizou-se o 
delineamento experimental inteiramente casualizado, e os tratamentos foram compostos pelas oito cultivares.

Durante o período de floração, foram marcados 40 botões florais de cada cultivar, divididos em quatro repetições, para posterior cálculo da percentagem de frutificação (Figura 1 D). Com a frutificação, o cálculo da percentagem foi realizado com a divisão do número de frutos fixados pelo número de botões marcados, e o resultado foi multiplicado por 100.

Para o cálculo da carpometria das cultivares, foram colhidos de cada cultivar de amoreira-preta, aleatoriamente, 20 frutos maduros (Figura 1 E), divididos em quatro repetições, para a determinação da massa fresca dos frutos, mensuração das dimensões dos frutos, além da contagem de quantidade, cálculo de massa e mensurações das dimensões dos drupetes e contagem do número de sementes. Posteriormente, foram separadas 120 sementes de cada cultivar, divididas em quatro repetições, que foram semeadas em bandejas de poliestireno expandido de 128 células, preenchidas com substrato à base de casca de pinus. As bandejas foram mantidas dentro de uma estufa de plástico (temperatura média de $25^{\circ} \mathrm{C}$ ) e irrigadas diariamente com auxílio de um borrifador. Passados 120 dias, realizou-se a contagem de plântulas emergidas (Figura 1 F) e, em seguida, calculou-se a percentagem de emergência.

Os dados foram submetidos à análise de variância, as médias qualitativas foram avaliadas pelo teste de comparação de médias de Scott-Knott, e os dados quantitativos foram submetidos à regressão linear ou quadrática, a $5 \%$ de probabilidade, pelo teste $\mathrm{F}$. As análises foram realizadas pelo Programa Sisvar (Ufla, Brasil).

\section{Resultados e Discussão}

Quanto à caracterização floral das cultivares de amoreira-preta, o número de pétalas da cultivar Caingangue foi superior ao das demais, que não diferiram entre si. Essa cultivar apresentou aproximadamente 11 pétalas por flor, enquanto as demais apresentaram, em média, somente cinco pétalas (Tabela 1). Não houve diferença significativa entre as cultivares, quanto ao número de sépalas, tendo-se observado, aproximadamente, cinco sépalas nas flores amostradas. Clark \& Finn (2011) também descrevem que as flores desta espécie são compostas por cinco sépalas e cinco pétalas de cor branca ou rosa, e que as flores duplas não são incomuns.

'Brazos' possui maior número de estames, com 67 a mais do que a BRS Tupy, que registrou o menor número de estames por flor, semelhantemente às cultivares Caingangue, Ébano e Guarani. 'Brazos' e 'Choctaw', cujos valores de carpelos foram os mais altos, apresentaram aproximadamente o dobro do valor da 'Cherokee', que obteve 75,90 carpelos, e foi a cultivar com menor quantidade de carpelos nas flores, junto com 'Caingangue', 'Comanche' e 'BRS Tupy'.

O número de estames foi variável entre cultivares, conforme relatado por Stanton et al. (2007), e até mesmo entre cultivares de outras Rosaceae, como relatou Albuquerque Junior et al. (2010) sobre macieira. As flores de amoreira-preta apresentam vários carpelos (Clark \& Finn, 2011), e o número destes também é variável entre os diferentes genótipos dessa cultura (Strik et al., 1996).

A maior quantidade de grãos de pólen por antera foi encontrada em 'Caingangue', 'Choctaw' e 'Guarani', enquanto a 'Ébano' e a 'BRS Tupy' apresentaram menores quantidades (Tabela 2). Quanto à quantidade de grãos de pólen por flor, 'Brazos', 'Choctaw' e 'Guarani' foram superiores às demais cultivares.

'Brazos' apresentou um número superior de grãos de pólen na flor, provavelmente em razão do elevado número de estames e, por consequência, de anteras presentes em suas flores (Tabela 1). 'Caingangue' não obteve um número tão considerável de grãos de pólen por flor, por causa do baixo número de estames presentes em suas flores, apesar de o número de

Tabela 1. Valores médios de número de pétalas, número de sépalas, número de estames e número de carpelos de flores de diferentes cultivares de amoreira-preta (Rubus spp. $)^{(1)}$.

\begin{tabular}{lcccr}
\hline Cultivar & $\begin{array}{c}\text { Pétalas } \\
\text { por flor }\end{array}$ & $\begin{array}{c}\text { Sépalas } \\
\text { por flor }\end{array}$ & $\begin{array}{c}\text { Estames } \\
\text { por flor }\end{array}$ & $\begin{array}{c}\text { Carpelos } \\
\text { por flor }\end{array}$ \\
\hline Brazos & $5,20 \mathrm{~b}$ & $5,10 \mathrm{a}$ & $181,20 \mathrm{a}$ & $159,20 \mathrm{a}$ \\
Caingangue & $11,50 \mathrm{a}$ & $5,20 \mathrm{a}$ & $123,60 \mathrm{c}$ & $93,00 \mathrm{c}$ \\
Cherokee & $5,50 \mathrm{~b}$ & $5,00 \mathrm{a}$ & $152,50 \mathrm{~b}$ & $75,90 \mathrm{c}$ \\
Choctaw & $4,80 \mathrm{~b}$ & $4,90 \mathrm{a}$ & $151,90 \mathrm{~b}$ & $143,90 \mathrm{a}$ \\
Comanche & $5,40 \mathrm{~b}$ & $5,40 \mathrm{a}$ & $148,50 \mathrm{~b}$ & $96,90 \mathrm{c}$ \\
Ébano & $5,20 \mathrm{~b}$ & $5,00 \mathrm{a}$ & $134,70 \mathrm{c}$ & $117,90 \mathrm{~b}$ \\
Guarani & $5,20 \mathrm{~b}$ & $5,20 \mathrm{a}$ & $137,10 \mathrm{c}$ & $112,00 \mathrm{~b}$ \\
BRS Tupy & $5,50 \mathrm{~b}$ & $5,20 \mathrm{a}$ & $114,40 \mathrm{c}$ & $90,50 \mathrm{c}$ \\
\hline CV $(\%)$ & 21,23 & 10,02 & 15,18 & 20,41 \\
\hline
\end{tabular}

(1)Médias seguidas de letras iguais, nas colunas, não diferem entre si, pelo teste de Scott-Knott, a 5\% de probabilidade. 
grãos de pólen contido na antera ser um dos maiores observados.

Mello Junior et al. (2011) ressaltam que nem sempre o maior número de anteras é indicativo de maior quantidade de grãos de pólen por flor. Essa afirmação corrobora os resultados obtidos no presente trabalho, em que a cultivar Guarani apresentou baixo número de estames (Tabela 1) e alta quantidade de grãos de pólen por flor (Tabela 2).

'Ébano' e 'BRS Tupy' também apresentaram baixo conteúdo de grãos de pólen em suas flores, provavelmente em consequência do baixo número de grãos de pólen observados na antera (Tabela 2) e do número inferior de estames encontrados em suas flores (Tabela 1).

Quanto aos experimentos realizados para estabelecer o meio de cultura adequado à germinação dos grãos de pólen, houve aumento linear na percentagem de germinação, à medida que se elevou o $\mathrm{pH}$ do meio; no maior $\mathrm{pH}$ testado $(6,5)$, a maior germinação $(25,97 \%)$ ocorreu na presença de $8 \mathrm{~g} \mathrm{~L}^{-1}$ de ágar, e a menor $(17,09 \%)$, à concentração de $4 \mathrm{~g} \mathrm{~L}^{-1}$ de ágar (Figura 2 A). Isso, provavelmente, ocorreu como resultado da alta inconsistência do meio, o que pode ter acarretado condições anaeróbicas e dificultado a germinação. Ramos et al. (2008) afirmam que ocorre aumento da germinação de grãos de pólen em citros, com o aumento do $\mathrm{pH}$ no meio de cultivo. A menor percentagem de germinação, obtida com $10 \mathrm{~g} \mathrm{~L}^{-1}$ de ágar, pode ser explicada pelo fato de esta concentração

Tabela 2. Valores médios de número de pólens por antera, número de pólens por flor e percentagem de germinação de grãos de pólen de diferentes cultivares de amoreira-preta (Rubus spp. $)^{(1)}$.

\begin{tabular}{lccc}
\hline Cultivar & $\begin{array}{c}\text { Pólens } \\
\text { por antera }\end{array}$ & $\begin{array}{c}\text { Pólens } \\
\text { por flor }\end{array}$ & $\begin{array}{c}\text { Germinação } \\
\text { de pólen (\%) }\end{array}$ \\
\hline Brazos & $113,96 \mathrm{~b}$ & $20.626,60 \mathrm{a}$ & $49,01 \mathrm{a}$ \\
Caingangue & $128,46 \mathrm{a}$ & $15.928,70 \mathrm{~b}$ & $28,70 \mathrm{c}$ \\
Cherokee & $108,88 \mathrm{~b}$ & $16.657,90 \mathrm{~b}$ & $40,89 \mathrm{~b}$ \\
Choctaw & $142,88 \mathrm{a}$ & $21.717,20 \mathrm{a}$ & $41,25 \mathrm{~b}$ \\
Comanche & $103,00 \mathrm{~b}$ & $15.350,70 \mathrm{~b}$ & $51,51 \mathrm{a}$ \\
Ébano & $76,79 \mathrm{c}$ & $10.366,90 \mathrm{c}$ & $26,58 \mathrm{c}$ \\
Guarani & $138,21 \mathrm{a}$ & $18.934,50 \mathrm{a}$ & $43,87 \mathrm{~b}$ \\
BRS Tupy & $83,42 \mathrm{c}$ & $9.509,40 \mathrm{c}$ & $27,75 \mathrm{c}$ \\
\hline CV $(\%)$ & 28,21 & 27,43 & 10,85 \\
\hline
\end{tabular}

${ }^{(1)}$ Médias seguidas de letras iguais, nas colunas, não diferem entre si, pelo teste de Scott-Knott, a 5\% de probabilidade. de ágar ter tornado o meio de cultura demasiadamente consistente, o que dificultou a absorção de água pelos grãos de pólen (Figura $2 \mathrm{~A}$ ). Beruto et al. (1995) mencionam que um meio de cultura muito sólido pode reduzir a disponibilidade de água e de sais minerais para o explante.

A percentagem de grãos de pólen germinados aumentou proporcionalmente, com a adição crescente das concentrações de sacarose ao meio de cultura. À concentração de $90 \mathrm{~g} \mathrm{~L}^{-1}$ de sacarose, conseguiu-se a germinação de 29,94\% de grãos de pólen (Figura 2 B). Aumento linear da percentagem de germinação dos grãos de pólen, à medida que se elevou a concentração de sacarose, também foi constatado por Chagas et al. (2010), em trabalhos realizados com pereira (Pyrus spp.). O efeito da adição de sacarose à germinação de grãos de pólen deve estar relacionado ao fornecimento de energia metabólica e a esqueletos carbônicos para a biossíntese de compostos orgânicos necessários ao crescimento das células (Caldas et al., 1998).

Na comparação de diferentes concentrações de ácido bórico e nitrato de cálcio adicionadas ao meio de cultura, observou-se que o nitrato de cálcio não foi essencial à germinação de grãos de pólen e que, na ausência deste, houve maior percentagem de germinação (33,31\%). Essa maior germinação foi obtida em presença de ácido bórico a $400 \mathrm{mg} \mathrm{L}^{-1}$ adicionados ao meio, que é a concentração estabelecida para compor o meio de cultura e dar continuidade aos próximos experimentos com amoreira-preta (Figura $2 \mathrm{C}$ ). A adição de boro também foi benéfica à germinação dos grãos de pólen de pereira (Chagas et al., 2010). O boro em presença de sacarose forma o complexo ionizável sacarose-borato, que reage mais rapidamente com as membranas celulares e facilita o desenvolvimento in vitro. Os resultados mostraram que apenas a presença do boro foi satisfatória para a germinação de grãos pólen. De acordo com Franzon \& Raseira (2006), o boro estimula o crescimento do tubo polínico e diminui a probabilidade de estes se romperem.

Verificou-se que a percentagem máxima de germinação $(52,50 \%)$ foi observada com cinco horas de incubação (Figura 2 D). Chagas et al. (2010) constataram que a germinação dos grãos de pólen de pereira teve início após uma hora da inoculação no meio. No presente trabalho, a germinação dos grãos de pólen começou já na primeira hora de incubação. 
Assim, quando se realiza um cruzamento em campo, a germinação dos grãos de pólen de amoreira-preta pode ser quase imediata.

A germinação dos grãos de pólen em meio de cultura acrescido de $90 \mathrm{~g} \mathrm{~L}^{-1}$ de sacarose e $400 \mathrm{mg} \mathrm{L}^{-1}$ de ácido bórico, com $\mathrm{pH}$ aferido para 6,5, e meio solidificado com $8 \mathrm{~g} \mathrm{~L}^{-1}$ de ágar diferiu entre as cultivares de amoreira-preta estudadas. As maiores percentagens de germinação foram observadas com as cultivares Brazos e Comanche (Tabela 2). As cultivares Cherokee, Choctaw e Guarani apresentaram germinação média superior à das cultivares Caingangue, Ébano e BRS Tupy. Essa diferença de germinação dos grãos de pólen, provavelmente, ocorreu em razão das características intrínsecas de cada cultivar e corroborou os resultados observados por Chagas et al. (2010), em estudo sobre diferentes cultivares de pereira.

Cultivares que apresentam maior quantidade de grãos de pólen, por antera e por flor, podem obter vantagem quanto à ação dos agentes polinizadores, já que flores e grãos de pólen de amoreira-preta são bem adaptados a insetos, particularmente para a polinização das abelhas (Clark \& Finn, 2011). Assim, pode haver aumento do número de drupetes e, consequentemente, da massa fresca do fruto, já que, flores polinizadas por abelhas geram frutos com maior quantidade de
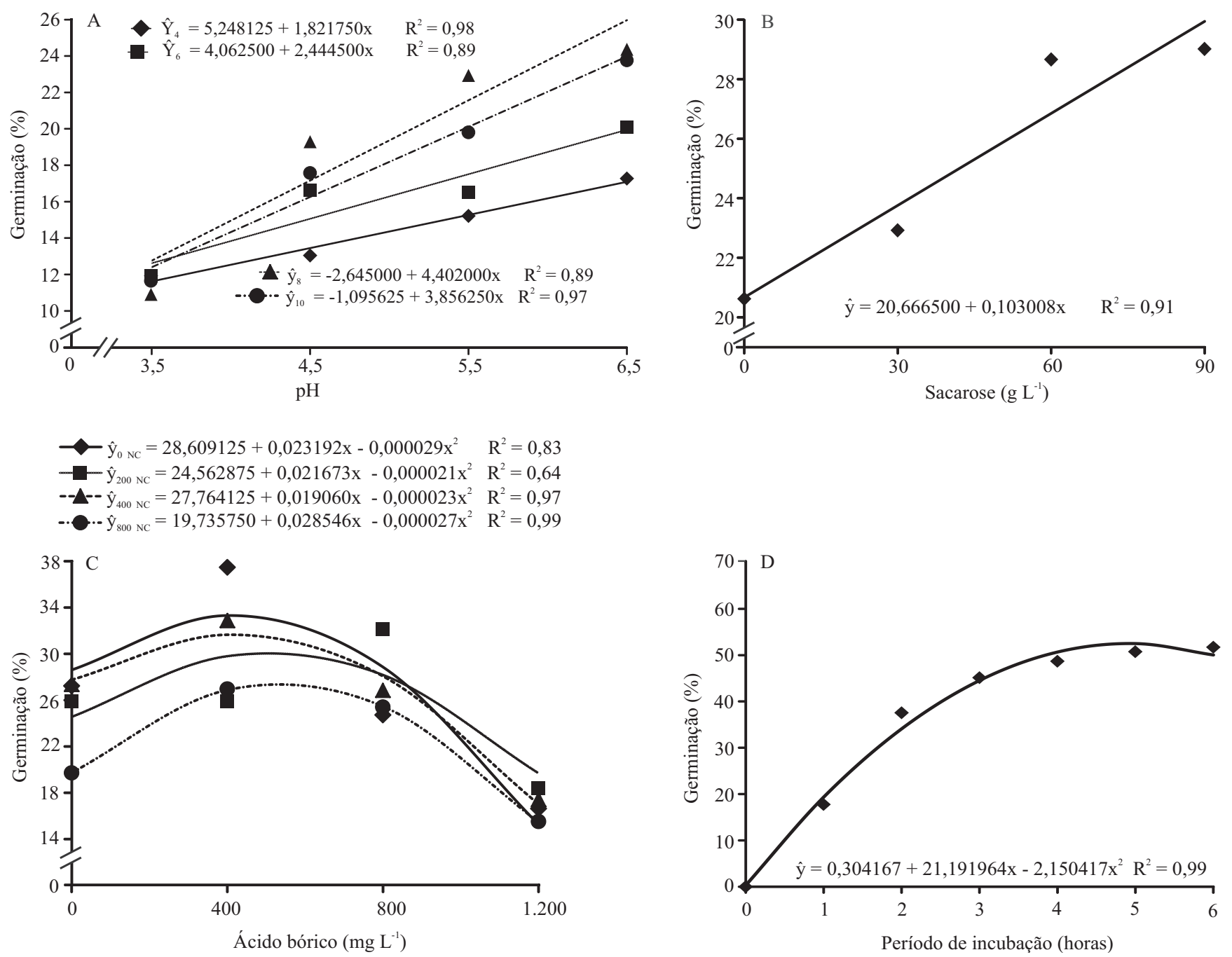

Figura 2. Percentagem de germinação, in vitro, de grãos de pólen da amoreira preta 'Comanche', submetidos a: A, diferentes pH e concentrações de ágar (4, 6, 8 e $10 \mathrm{~g} \mathrm{~L}^{-1}$ ) do meio de cultura; B, diferentes concentrações de sacarose; C, diferentes concentrações de ácido bórico e nitrato de cálcio $\left(\mathrm{NC}, \mathrm{mg} \mathrm{L}^{-1}\right)$; e $\mathrm{D}$, diferentes períodos de incubação. 
drupetes, do que por autopolinização (Cane, 2005). Mello Junior et al. (2011) verificaram que flores polinizadas por abelhas fixaram quatro vezes mais drupetes do que as flores que foram autopolinizadas. Além disso, é desejável que a cultivar apresente alta germinação de seus grãos de pólen. Entretanto, em amoreira-preta, essa relação foi observada apenas com a cultivar Brazos, que apresentou a maior quantidade de grãos de pólen por flor, de carpelos e de estames e, ainda, a maior germinação de seus grãos de pólen, em comparação às demais cultivares (Tabelas 1 e 2).

Para a cultivar Brazos, registraram-se frutos com maior massa e, consequentemente, maior dimensão, que não diferiu da Guarani (Tabela 3). Essas duas cultivares também apresentaram o maior número de drupetes, juntamente com a 'Choctaw'. Era esperado que a 'Choctaw' tivesse frutos com maior quantidade de drupetes, uma vez que apresentou maior número de carpelos do que as demais cultivares (Tabela 1). Porém, verificou-se que os drupetes dessa cultivar foram os de menor massa e dimensões (Tabela 3), que também resultou em frutos de menor massa. A cultivar Ébano apresentou drupetes com maior massa e dimensões, porém com frutos de menor massa, provavelmente em consequência de menor número de drupetes por fruto.

'Ébano' obteve o menor comprimento de fruto, com um dos maiores diâmetros, o que mostra que o fruto dessa cultivar é um pouco mais arredondado do que os das demais cultivares. Os frutos da 'Brazos' foram maiores e apresentaram aproximadamente o dobro da massa dos frutos da cultivar Cherokee.
A maior quantidade de sementes foi observada nos frutos das cultivares Brazos e Choctaw (Tabela 3). Apesar de a 'Guarani' não ter sido estatisticamente igual às cultivares Brazos e Choctaw, ela apresentou um número alto de sementes por fruto, o que indica que essas características, provavelmente, se relacionam com o número de drupetes Clark \& Finn (2011). A quantidade de sementes de frutos da 'Comanche' e da 'Ébano' foi aproximadamente duas vezes menor do que a encontrada nas cultivares que apresentaram maior número de sementes.

Não houve diferença estatística entre as percentagens de frutificação das cultivares. Contudo, verificou-se que os valores foram elevados, o que poderá provavelmente acarretar uma produção uniforme. As cultivares Choctaw e Comanche apresentaram baixa emergência de plântulas (Tabela 3), possivelmente em consequência da forte dormência existente nas sementes da espécie Rubus (Maeda \& Coelho, 1995). 'Brazos' e 'Guarani' apresentaram maior emergência de plântulas, o que significa que suas sementes não necessitam de tratamentos químicos, físicos ou mecânicos para superação de dormência. Este resultado é importante para programas de melhoramento genético, pois possibilita a avaliação das progênies obtidas de cruzamentos com maior rapidez e maior confiabilidade, além de não afetar a qualidade da semente e, possivelmente, de oferecer considerável quantidade de plântulas melhoradas. Antunes et al. (2000) também verificaram que essas cultivares produzem maior quantidade de frutos em regiões subtropicais e

Tabela 3. Valores médios de massa de fruto (MF), comprimento de fruto (CF), diâmetro de fruto (DF), número de drupetes (ND), massa de drupetes (MD), comprimento de drupetes (CD), diâmetro de drupetes (DD), número de sementes de frutos (NS), percentagem de frutificação (PF) e percentagem de emergência (PE) de plântulas de diferentes cultivares de amoreirapreta (Rubus spp.) $)^{(1)}$.

\begin{tabular}{|c|c|c|c|c|c|c|c|c|c|c|}
\hline Cultivar & $\mathrm{MF}(\mathrm{g})$ & $\mathrm{CF}(\mathrm{mm})$ & $\mathrm{DF}(\mathrm{mm})$ & ND (unidade) & $\mathrm{MD}(\mathrm{g})$ & $\mathrm{CD}(\mathrm{mm})$ & $\mathrm{DD}(\mathrm{mm})$ & NS (unidade) & PF (\%) & $\mathrm{PE}(\%)$ \\
\hline Brazos & $9,26 \mathrm{a}$ & $29,25 \mathrm{a}$ & $23,42 \mathrm{a}$ & $86,20 \mathrm{a}$ & $0,11 b$ & $5,13 b$ & $4,52 b$ & $88,05 \mathrm{a}$ & $92,50 \mathrm{a}$ & $76,66 a$ \\
\hline Caingangue & $4,83 \mathrm{~d}$ & $20,69 \mathrm{c}$ & $20,14 b$ & $48,55 \mathrm{c}$ & $0,10 \mathrm{~b}$ & $5,06 \mathrm{~b}$ & $4,51 b$ & $53,55 d$ & $87,50 \mathrm{a}$ & $22,50 \mathrm{~b}$ \\
\hline Cherokee & $4,76 \mathrm{~d}$ & $21,89 \mathrm{c}$ & $19,84 b$ & $51,15 c$ & $0,10 \mathrm{~b}$ & $5,24 b$ & $4,71 b$ & $48,75 \mathrm{~d}$ & $90,00 \mathrm{a}$ & $19,17 b$ \\
\hline Choctaw & $5,87 \mathrm{c}$ & $22,49 \mathrm{c}$ & $21,19 b$ & $81,00 \mathrm{a}$ & $0,07 \mathrm{c}$ & $4,48 \mathrm{c}$ & $4,07 \mathrm{c}$ & $84,65 a$ & $95,00 \mathrm{a}$ & $3,33 \mathrm{c}$ \\
\hline Comanche & $5,38 \mathrm{c}$ & $23,02 \mathrm{c}$ & $20,25 b$ & $50,55 \mathrm{c}$ & $0,11 b$ & $5,34 \mathrm{~b}$ & $4,73 b$ & $40,75 \mathrm{e}$ & $92,50 \mathrm{a}$ & $4,17 \mathrm{c}$ \\
\hline Ébano & $5,28 \mathrm{c}$ & $21,35 \mathrm{c}$ & $22,58 \mathrm{a}$ & $31,05 d$ & $0,17 \mathrm{a}$ & $6,58 \mathrm{a}$ & $5,99 \mathrm{a}$ & $38,39 \mathrm{e}$ & $90,00 \mathrm{a}$ & $12,50 \mathrm{~b}$ \\
\hline Guarani & $8,52 \mathrm{a}$ & $28,73 a$ & $23,66 \mathrm{a}$ & $75,80 \mathrm{a}$ & $0,11 b$ & $5,22 b$ & $4,75 b$ & $75,35 b$ & $95,00 \mathrm{a}$ & $67,50 \mathrm{a}$ \\
\hline BRS Tupy & $7,56 \mathrm{~b}$ & $25,90 \mathrm{~b}$ & $22,03 \mathrm{a}$ & $62,15 b$ & $0,12 \mathrm{~b}$ & $5,29 \mathrm{~b}$ & $4,85 \mathrm{~b}$ & $63,75 \mathrm{c}$ & $92,50 \mathrm{a}$ & $20,00 \mathrm{~b}$ \\
\hline $\mathrm{CV}(\%)$ & 9,54 & 5,20 & 5,77 & 8,39 & 9,76 & 5,97 & 6,06 & 10,86 & 10,66 & 28,29 \\
\hline
\end{tabular}

${ }^{(1)}$ Médias seguidas de letras iguais, nas colunas, não diferem entre si, pelo teste de Scott-Knott, a 5\% de probabilidade. 
são aptas para utilização nas hibridações controladas. Além disso, são cultivares que apresentam boa capacidade rizogênica de estacas, fator importante na multiplicação varietal (Campagnolo \& Pio, 2012a).

\section{Conclusões}

1. Há necessidade de intensificação das hibridações em campo, na utilização das cultivares Caingangue, Ébano e BRS Tupy, quando estas forem doadoras de grãos de pólen.

2. 'Choctaw' e 'Comanche' apresentam baixa percentagem de emergência de plântulas e, se utilizadas como plantas progenitoras, podem reduzir a rapidez da avaliação de progênies após cruzamentos.

3. A cultivar de amoreira-preta Brazos se destaca quanto às características florais e carpométricas, bem como quanto à germinação de seus grãos de pólen e emergência de plântulas, e pode ser uma boa progenitora para utilização em programas de melhoramento genético.

\section{Agradecimentos}

À Coordenação de Aperfeiçoamento de Pessoal de Nível Superior (Capes), ao Conselho Nacional de Desenvolvimento Científico e Tecnológico (CNPq) e à Fundação de Amparo à Pesquisa do Estado de Minas Gerais (Fapemig), por apoio financeiro e concessão de bolsas.

\section{Referências}

ALBUQUERQUE JUNIOR, C.L. de; DENARDI, F.; DANTAS, A.C. de M.; NODARI, R.O. Número de anteras por flor, grãos de pólen por antera e capacidade germinativa do pólen de diferentes cultivares de macieiras. Revista Brasileira de Fruticultura, v.32, p.1255-1260, 2010. DOI: 10.1590/S0100-29452010005000129.

ALICE, L.A. Evolutionary relationships in Rubus (Rosaceae) based on molecular data. Acta Horticulturae, v.585, p.79-83, 2002.

ANTUNES, L.E.C.; CHALFUN, N.N.J.; REGINA, M. de A.; DUARTE FILHO, J. Fenologia e produção de variedades de amora-preta nas condições do planalto de Poços de Caldas-MG. Revista Brasileira de Fruticultura, v.22, p.89-95, 2000.

ANTUNES, L.E.C.; TREVISAN, R.; GONÇALVES, E.D. Propagação, plantio e tratos culturais. In: ANTUNES, L.E.C.; RESEIRA, M. do C.B. Aspectos técnicos da cultura da amora-preta. Pelotas: Embrapa Clima Temperado, 2004. p.37-42. (Embrapa Clima Temperado. Documentos, 122).

BERUTO, D.; BERUTO, M.; CICCARELLI, C.; DEBERGH, P. Matric potential evaluations and measurements for gelled substrates. Physiologia Plantarum, v.94, p.151-157, 1995. DOI: 10.1111/j.1399-3054.1995.tb00796.x.

BOLAT, I.; PIRLAK, L. An investigation on pollen viability, germination and tube growth in some stone fruits. Turkish Journal of Agriculture and Forestry, v.23, p.383-388, 1999.

CALDAS, L.S.; HARIDASAN, P.; FERREIRA, M.E. Meios nutritivos. In: TORRES, A.C.; CALDAS, L.S.; BUSO, J.A. Cultura de tecidos e transformação genética de plantas. Brasília: Embrapa-SPI: Embrapa-CNPH, 1998. v.1, p.87-132.

CAMPAGNOLO, M.A.; PIO, R. Enraizamento de estacas caulinares e radiculares de cultivares de amoreira-preta coletadas em diferentes épocas, armazenadas a frio e tratadas com AIB. Ciência Rural, v.42, p.232-237, 2012a. DOI: 10.1590/ S0103-84782012000200008.

CAMPAGNOLO, M.A.; PIO, R. Phenological and yield performance of black and redberry cultivars in western Paraná state. Acta Scientiarum. Agronomy, v.34, p.439-444, 2012 b. DOI: 10.4025 /actasciagron.v34i4.15528.

CAMPAGNOLO, M.A.; PIO, R. Produção da amoreira-preta 'Tupy' sob diferentes épocas de poda. Ciência Rural, v.42, p.225-231, 2012c. DOI: 10.1590/S0103-84782012005000007.

CANE, J.H. Pollination potential of the bee Osmia aglaia for cultivated red raspberries and blackberries (Rubus: Rosaceae). HortScience, v.40, p.1705-1708, 2005.

CHAGAS, E.A.; PIO, R.; CHAGAS, P.C.; PASQUAL, M.; BETTIOL NETO, J.E. Composição do meio de cultura e condições ambientais para germinação de grãos de pólen de porta-enxertos de pereira. Ciência Rural, v.40, p.261-266, 2010. DOI: 10.1590/ S0103-84782010000200002.

CLARK, J.R. Primocane-fruiting blackberry breeding. HortScience, v.43, p.1637-1639, 2008.

CLARK, J.R.; FINN, C.E. Blackberry breeding and genetics. Fruit, Vegetable and Cereal Science and Biotechnology, v.5, p.27-43, 2011.

FRANZON, R.C.; RASEIRA, M. do C.B. Germinação in vitro e armazenamento do pólen de Eugenia involucrata DC (Myrtaceae). Revista Brasileira de Fruticultura, v.28, p.18-20, 2006. DOI: 10.1590/S0100-29452006000100008.

GUEDES, M.N.S.; ABREU, C.M.P. de; MARO, L.A.C.; PIO, R.; ABREU, J.R. de; OLIVEIRA, J.O. de. Chemical characterization and mineral levels in the fruits of blackberry cultivars grown in a tropical climate at an elevation. Acta Scientiarum. Agronomy, v.32, p.191-196, 2013. DOI: 10.4025/actasciagron.v35i2.16630.

MAEDA, J.A.; COELHO, S.M.B.M. Germinação e dormência de sementes de framboesa (Rubus idaeus L.). Revista Brasileira de Sementes, v.17, p.101-106, 1995.

MELLO JUNIOR, L.J. de; ORTH, A.I.; MORETTO, G. Ecologia da polinização da amoreira-preta (Rubus sp.) (Rosaceae) em Timbó-SC, Brasil. Revista Brasileira de Fruticultura, v.33, p.1015-1018, 2011. DOI: 10.1590/S0100-29452011005000096.

PIO, R.; MOURÃO FILHO, F. de A.A.; MENDES, B.M.J.; ANGELI, S. de S.; ALVES, A.S.R.; AZEVEDO, F.A.; BETTIOL NETO, J.E. Biologia floral de híbridos somáticos e porta-enxertos de citros. Laranja, v.26, p.95-108, 2005. 
RAMOS, J.D.; PASQUAL, M.; SALLES, L.A.; CHAGAS, E.A.; PIO, R. Receptividade do estigma e ajuste de protocolo para germinação in vitro de grãos de pólen de citros. Interciência, v.33, p.51-55, 2008.

RASEIRA, M. do C.B.; FRANZON, R.C. Melhoramento genético e cultivares de amora-preta e mirtilo. Informe Agropecuário, v.33, p.11-20, 2012.
STANTON, M.A.; SCHEERENS, J.C.; FUNT, R.C.; CLARK, J.R. Floral competence of primocane-fruiting blackberries prime-jan and prime-jim grown at three temperature regimens. HortScience, v.42, p.508-513, 2007.

STRIK, B.C.; MANN, J.; FINN, C. Percent drupelet set varies among blackberry genotypes. Journal of the American Society for Horticultural Science, v.121, p.371-373, 1996.

Recebido em 9 de novembro de 2012 e aprovado em 7 de junho de 2013 